\title{
Разработка теплообменника с неподвижной гранулированной насад- кой для утилизации низкопотенциальной теплоты
}

\author{
И. Л. Бошкова ${ }^{1}$ Н.В. Волгушева ${ }^{2}$ А. В. Солодкая ${ }^{3}$ \\ Одесская национальная академия пищевых технологий, ул. Канатная, 112, Одесса, 65039, Украина \\ e-mail: ${ }^{1}$ boshkova.irina@gmail.com, ${ }^{2}$ natvolgusheva@ gmail.com, ${ }^{3}$ solodkaya140619@ gmail.com \\ ORCID: ${ }^{1}$ http://orcid.org/0000-0001-5989-9223; ${ }^{2}$ http://orcid.org/0000-0002-9984-6502; \\ ${ }^{3}$ http://orcid.org/0000-0002-4043-7667
}

\begin{abstract}
Рассматривается использование теплообменника-регенератора с гранулированной насадкой для утилизации низкопотенциильной теплоты отходящих газов. Приведена методика теплового расчета регенератора с неподвижной насадкой гранулированного материала. Представлена эмпирическая зависимость для расчета коэффициента межкомпонентного теплообмена. Проведено сопоставление основных характеристик теплообменников с движушимся и неподвижным слоем.
\end{abstract}

Ключевые слова: Отходящие газы; Утилизация; Теплообменник; Гранулированная насадка; Методика расчета; Эффективность.

\section{Розробка теплообмінника з нерухомою гранульованою насадкою для утилізації низькопотенційної теплоти}

\section{І. Л. Бошкова, Н. В. Волгушева, А. В. Солодка}

Одеська національна академія харчових технологій, вул. Канатна, 112, Одеса, 65039, Україна

\begin{abstract}
Розглядаються теплообмінники регенеративного типу з гранульованої насадкою, призначені для утилізації теплоти відхідних газів. Відзначається, щзо використання проточних дисперсних теплоносії дозволяє інтенсифікувати процеси теплообміну, що відкриває перспективи використання контактних теплообмінників для утилізаиії низькопотениійної теплоти відхідних газів. Представлена методика теплового конструкторського розрахунку теплообмінника з нерухомою насадкою. Для визначення коефіцієнта міжкомпонентноео теплообміну запропонована емпірична залежність в безрозмірному вигляді, отримана в результаті обробки експериментальних даних за дослідженням теплообміну між потоком газоподібного теплоносія $і$ шаром твердих частинок. Наведено результати розрахунку теплообмінника за представленою методикою. Отримано значення основних геометричних і фізичних характеристик: обсяг теплообмінної ділянки, висота, маса гранульованої насадки, тривалість періоду нагріву. Зіставлення з аналогічними характеристиками для теплообмінника з рухомої насадкою показує перевагу останнього у ефективності (тепловому ККД). Однак при використанні теплообмінника з нерухомою насадкою не виникає необхідності в організації безперервного руху шару гранульованого матеріалу, щзо істотно спрощує експлуатаціюю і конструкцію теплообмінника.
\end{abstract}

Ключові слова: Відхідні гази; Утилізачія; Теплообмінник; Гранульована насадка; Методика розрахунку; Ефективність.

(C) The Author(s) 2018. This article is an open access publication

This work is licensed under the Creative Commons Attribution 4.0 International License (CC BY) http://creativecommons.org/licenses/by/4.0/

\section{1. Введение}

Значительную часть тепловых потерь в энергетических и теплотехнологических установках различного назначения представляет физическая теплота отходящих газов, использование которой может быть направлено на повышение эффективности производственных процессов. Однако целесообразность утилизации теплоты не всегда оправдана, что связано, в основном, с недостатком разработок эффективных теплоутилизаторов, в частности, для утилизации низкопотенциальной теплоты (температура отходящих газов не превышает $\left.100{ }^{\circ} \mathrm{C}\right)$. Особый интерес представляют теплоутилизационные установки, которые обеспечивают непосредственный теплообмен газа со слоем частиц (гранулированной насадкой) $[1,2]$. Использование таких проточных дисперсных теплоносителей в теплоэнергетике позволяет интенсифицировать процессы тепло- и массообмена $[3,4,5]$. Теплоутилизаторы с гранулированной насадкой обладают рядом преимуществ: развитая поверхность теплообмена, простота конструкции, высокая эффективность $[6,7,8]$, что определяет большой 
потенциал их применения для утилизации теплоты отходящих газов на промышленных предприятиях относительно незначительной энергетической мощности, в частности, пищевых. К способам использования низкопотенциальных ВЭР относится предварительный подогрев воздуха в системах вентиляции, воды для горячего водоснабжения и автономных систем отопления. Однако для промышленного внедрения недостаточно надежных данных по теплообмену между плотным слоем гранул и газом. Проектирование подобных контактных теплообменников зависит от инженерной модели расчета основных конструктивных характеристик теплообменного участка.

Процесс аккумуляции тепловой энергии в стационарном регенеративном теплоутилизаторе, в котором используется гранулированная насадка, характеризуется двумя режимами работы: режим аккумуляции и режим регенерации [9]. В режиме аккумуляции устройство работает на вытяжку и происходит нагрев регенеративной насадки внутренним вытяжным воздухом. В режиме регенерации устройство работает на приток и происходит нагрев приточного воздуха насадкой. Сложность рассматриваемых физических явлений и многообразие физических особенностей гранулированного материала существенно затрудняют создание единой теоретической модели [10].

Применяются теплоутилизаторы с гранулированной движущейся и неподвижной насадкой в виде плотного слоя. Если методики расчета теплоутилизаторов с движущимся слоем достаточно хорошо разработаны $[2,5]$, то для теплоутилизаторов с неподвижным слоем при создании методик возникают большие сложности, связанные с тем, что рассматриваемые регенеративные теплообменники работают в периодическом нестационарном режиме. Для инженерных расчетов используются приближенные методы [11]. Расчеты ведут по средним за период характеристикам, тепловой поток относят не к единице времени, а к периоду.

\section{2. Методика теплового расчета теплообменни- ка-регенератора с неподвижной гранулирован- ной насадкой}

При создании методов расчетов теплообменникарегенератора с неподвижной гранулированной насадкой (ТРНГН) возникают определенные трудности, связанные с особенностью их работы в конкретных условиях. Поэтому для утилизации низкопотенциальной теплоты возникла необходимость в разработке методики расчета ТРНГН. Предварительно проведенные экспериментальные исследования показали, что коэффициент межкомпонентного теплообмена $\bar{\alpha}_{\mu}$ существенно изменяется во времени. Поэтому представлять зависимости для определения $\bar{\alpha}_{м}$ в виде $N u=f(\mathrm{Re})$, что распространено при обобщении данных для аппаратов с движущимся слоем в стационарном режиме, нерационально. Как было получено при анализе опытных данных, зависимость коэффициента межкомпонентного теплообмена от времени с высокой степенью точности описывается сигмоидой [12]. В результате обобщения экспериментальных данных была получена зависимость в безразмерном виде для расчета среднего по высоте коэффициента межкомпонентного теплообмена (1):

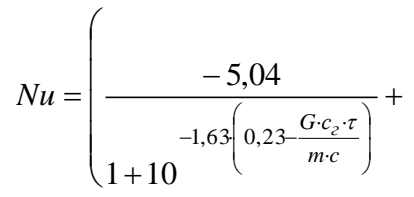

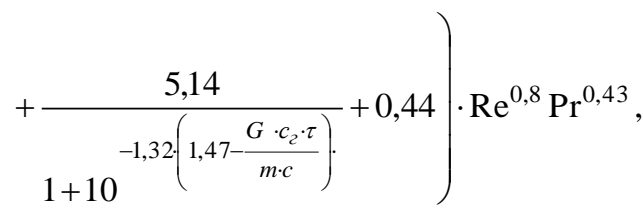

где $N u=\frac{\alpha_{M} \cdot d_{e}}{\lambda_{2}}, \operatorname{Re}=\frac{w_{\phi} \cdot d_{e}}{v_{2}}$.

Зависимость позволяет рассчитать $\bar{\alpha}_{\mu}$ в заданный момент времени $\tau$ при заданном значении расхода газового потока $G$ и массе загрузки гранулированного материала $\mathrm{m}$ c теплоемкостью $c$ при теплообмене между газовой средой и гранулированным материалом в цилиндрическом канале. Условия применимости данной зависимости следующие: гранулированный материал - щебень и керамзит с эквивалентным диаметром частиц $\mathrm{d}_{\ni}=0,0019-0,0021 \mathrm{M}, \quad$ теплоемкостью $\mathrm{c}=750-840$ Дж/(кг К), температурой газа на входе в аппарат $\mathrm{t}=50-80^{\circ} \mathrm{C}$, расходом $G=0,010-0,012 \mathrm{\kappa г} / \mathrm{c}$.

Расчет ведется методом последовательным приближений. Для проведения расчета необходимо выбрать: гранулированный материал с эквивалентным диаметром частиц $\mathrm{d}_{э}$, а также предварительно задаться следующими величинами: $\bar{\alpha}_{M}, G$, диаметром канала $D$, температурой газа на входе $t_{\Gamma}^{\prime}$, начальной температурой слоя материала $t_{M}^{\prime}$, конечной температурой материала $t_{M}^{\tau}=0,8 \cdot t_{\Gamma}^{\prime},{ }^{\circ} \mathrm{C}$ (согласно рекомендациям, полученным на основании анализа экспериментальных данных),

Расчет ведется методом последовательных приближений по следующему алгоритму.

1. Средние значения температур газового и твердого компонентов:

$$
\begin{gathered}
\bar{t}_{2}=\frac{t_{2}^{\prime}+\bar{t}_{2}^{\prime \prime}}{2},{ }^{\circ} \mathrm{C} ; \\
\bar{t}_{M}=\frac{t_{M}^{\prime}+t_{M \cdot \max }^{\prime \prime}}{2},{ }^{\circ} \mathrm{C} .
\end{gathered}
$$

2. По $\bar{t}_{2},{ }^{\circ} \mathrm{C}$ определить теплофизические характеристики газовой среды: $v_{2}, c_{p}, \lambda_{2}, \rho_{2}, P r$.

3. Скорость фильтрации газовой среды:

$$
w_{\phi}=\frac{G}{\rho_{2} \cdot S}, \mathrm{M} / \mathrm{c} .
$$

4. Число Рейнольдса:

$$
\operatorname{Re}_{2}=\frac{w_{\phi} \cdot D}{v_{2}} .
$$

5. Средний тепловой поток в теплообменнике:

$$
\bar{Q}=G \cdot c_{p} \cdot\left(t_{2}{ }^{\prime}-\frac{t_{M}^{\prime}+t_{2 .}^{\prime \prime}}{2}\right), \text { Вт. }
$$


6. Площадь поверхности гранулированного материала $F_{M}$

$$
F_{M}=\frac{Q}{\bar{\alpha}_{M} \cdot \Delta \bar{t}}, \mathrm{M}^{2}
$$

где $\Delta \bar{t}_{n}=\bar{t}_{2}-t_{M}^{\tau},{ }^{\circ} \mathrm{C}$.

7. Масса загрузки материала (определяется по следующему алгоритму):

$$
F_{M} \cdot \varphi_{u}=4 \pi \cdot\left(\frac{d_{\ni}}{2}\right)^{2} \cdot n \rightarrow n=\frac{F_{M} \cdot \varphi_{u}}{4 \pi \cdot\left(\frac{d_{e}}{2}\right)^{2}},
$$

где $\varphi_{ч}-$ коэффициент формы частиц;

$$
m_{M}=V \cdot \rho_{M} \cdot n=\frac{4}{3} \pi\left(\frac{d_{\ni}}{2}\right)^{3} \cdot \rho_{M} \cdot n, \mathrm{\kappa г.}
$$

8. Продолжительность нагрева:

$$
\tau=\frac{m_{M} \cdot c_{p} \cdot\left(t_{M}^{\tau}-t_{M}^{\prime}\right)}{Q}, \mathbf{c} .
$$

9. $\alpha_{м i}$ в промежутке времени $\Delta \tau$ (по уравнению (1)).

10. Среднее во времени $\bar{\alpha}_{M}$, как средневзвешенная величина по $\alpha_{\text {мi }}$, для периода времени от 0 до $\tau$ :

$$
\bar{\alpha}_{M}=\sum_{i=1}^{n} \frac{\alpha_{M i} \cdot \Delta \tau}{\tau}
$$

11. Определяем отклонение заданного в первом приближении значения $\bar{\alpha}_{M}$ от рассчитанного. Если расхождение $\bar{\alpha}_{\mu}$ (по п. 10) с заданным $\bar{\alpha}_{M}$ составляет более $5 \%$, следует принять $\bar{\alpha}_{M}$ из п. 10 и провести расчет во втором приближении.

Расчет повторяется до удовлетворительного согласования значений $\bar{\alpha}_{\mathcal{M}}$.

12. При удовлетворительном согласовании расчет считать завершенным. Как результат, получены значения величин: $F_{M}, \mathrm{M}^{2} ; Q, \mathrm{Bт} ; m_{\mathcal{M}}$, кг; $\tau$, с.

13. Объем аппарата:

$$
V=\frac{F_{M}}{a_{y \partial}}, \mathrm{m}^{3},
$$

где $a_{y \partial}=\frac{6(1-\varepsilon)}{d_{e}}, \mathrm{M}^{2} / \mathrm{M}^{3}$

14. Высота камери $\mathrm{H}: H=V / S$, м, где $\mathrm{S}-$ площадь поперечного сечения канала.

Разработанная методика отличается тем, что учитывается изменение коэффициента межкомпонентного теплообмена во временеми. Это позволяет получить более точные данные по значению площади теплообменной поверхности, соответственно, объема теплообменного аппарата и продолжительности периодов аккумуляции и регенерации.

\section{3. Результаты расчета промышленного ТРНГН}

Тепловой расчет проведен для ТРНГН, предназначенный для утилизации низкопотенциальной теплоты отходящих газов с расходом $G_{2}=400 \mathrm{~m}^{3} / \mathrm{4}, t_{2}{ }^{\prime}=80^{\circ} \mathrm{C}$. Принято: $\bar{\alpha}_{M}=50$ Вт/м ${ }^{2} \mathrm{~K}$ (в первом приближении), $t_{M}{ }^{\prime}=20^{\circ} \mathrm{C} ; t_{M}{ }^{\prime \prime}=0,8 \cdot t_{n}{ }^{\prime}=0,8 \cdot 80=64{ }^{\circ} \mathrm{C}$. Материал - ке- рамзит, $\mathrm{d}_{\ni}=0,02 \mathrm{M}$, диаметр канала $\mathrm{D}=0,2$ м. В результате расчета по приведенной методике получено: $\bar{\alpha}_{M}=112,5 \mathrm{BT} / \mathrm{M}^{2} \mathrm{~K}, \quad F_{M}=1,48 \mathrm{~m}^{2}, \quad Q=4068$ Вт; масса засыпки керамзита в аппарате $m_{M}=11$ кг; длительность периода аккумуляции $\tau=92 \mathrm{c}$. Объем аппарата $\mathrm{V}=0,0085 \mathrm{~m}^{3}$, высота слоя гранулированного материала $\mathrm{H}=3,0$ м.

Общепринятым условием «идеальности» теплообменника считается достижение схождения температур теплоносителей при установившемся теплообмене [13], что определяется коэффициентом эффективности (КПД). Эффективность данного ТРНГН:

$$
\varepsilon=\frac{t_{n}^{\prime}-\frac{t_{n}^{H}+t_{n}^{\kappa}}{2}}{t_{n}^{\prime}-t_{n}^{H}}=0,6 .
$$

Для оценки перспективности использования теплообменника-регенератора с неподвижной гранулированной насадкой проведено сопоставление его характеристик с теплообменником-регенератором с движущейся гранулированной насадкой (ТРДГН), расчет которого проводился по методике [14] при аналогичных исходных данных. Их сравнительные характеристики приведены в таблице 1 .

Таблица 1 - Основные характеристики ТРНГН и ТРДГН

\begin{tabular}{|c|c|c|}
\hline Величина & $\begin{array}{c}\text { Движущийся } \\
\text { слой }\end{array}$ & $\begin{array}{c}\text { Неподвижный } \\
\text { слой }\end{array}$ \\
\hline $\begin{array}{c}\text { Высота теплооб- } \\
\text { менного участка, м }\end{array}$ & 0,8 & 3,0 \\
\hline Время нагрева, с & - & 92 \\
\hline $\begin{array}{c}\text { Расход воздуха, } \\
\text { кг/с }\end{array}$ & 0,11 & 0,11 \\
\hline $\begin{array}{c}\text { Расход } \\
\text { материала, кг/с }\end{array}$ & 0,23 & - \\
\hline $\begin{array}{c}\text { Скорость } \\
\text { фильтрации, м/с }\end{array}$ & 3,3 & 0,4 \\
\hline Эффекктивность & 0,75 & 0,6 \\
\hline
\end{tabular}

Анализ полученных результатов показывает, что эффективность теплообменника с движущимся слоем выше, чем с неподвижным. Однако следует отметить, что значение эффективности $\varepsilon=0,6$ для существующих теплообменников является хорошим показателем. Высота теплообменного участка выше для ТРНГН, однако при этом не возникает необходимости в организации непрерывного движения слоя гранулированного материала, что существенно упрощает эксплуатацию и конструкцию теплообменника.

\section{Выводы}

Предложенная методика теплового расчета теплообменника-регенератора с неподвижной гранулированной насадкой, предназначенного для утилизации низкопотенциальной теплоты отходящих газов, позволяет оценить основные геометрические характеристики аппарата, длительность периода нагрева и его эффективность. В сравнении с теплообменником-регенератором 
с движущейся насадкой эффективность ниже, однако изготовление и эксплуатация аппарата с неподвижной гранулированной насадкой значительно проще.

\section{Литература}

1. Прутских Д. А. Гидродинамика и теплообмен в регенераторе с дисперсной насадкой // Автореферат дисс. на соискание уч. степени к. т. н. Специальность: 05.14.04 - Промышленная теплоэнергетика. - Воронеж: 2009. $-22 \mathrm{c}$

2. Медведев В. Б. Моделирование и расчет тепловых процессов в регенеративных утилизаторах теплоты с циркулирующей гранулированной насадкой : автореф. дис. ... канд. техн. наук: 05.17.08 // В.Б. Медведев; [Ивановский гос. энергетический унив-т]. - Иваново, 2009. $-17 \mathrm{c}$

3. Yulong D., Yurong H., Wei Ngoc Y. Hydrodynamics and heat transfer of gas-solid two-phase mixtures flowing through packed beds // Progress in Natural Science. 2008.-Vol. 18. - P. 1185-1196.

4. Snider D. M., Dale M. S. Three fundamental granular flow experiments and CPFD predictions // Power Technology. - 2007. - Vol. 176.- P. 36-46.

5. Рева Л. С. Методы гидродинамического и теплового расчета теплообменников с зернистой насадкой: дисс. ... канд. техн. наук. - Волгоград, 1984. - 260 с.

6. Yu J., Zhang M., Fan W., Zhou Y., Zhao G. Study on performance of the ball packed-bed regenerator: experiments and simulation // Applied Thermal Engineering. 2014. - Vol. 69. P.113-122.

7. Nie X. D., Besant R. W., Evitts R. W. Heat transfer between gas-solid phases within packed particle beds // Particulate science and technology: an international journal. - 2010. -Vol. 29, №2. P.151-162.

8. Бошкова І.Л., Солодка А.В. Исследование эффективности теплообмена в теплообменниках-утилиза- торах с гранулированной насадкой // Аспекты регионального развития Матеріали міжнародної наукової конференції. - Молдова, Кишинів: Институт энергетики АН Молдовы, 2016. - С. 373-377.

9. Монаркин Н.Н., Наимов А.Н., Синицын А.А., Рогулина Т.В. Математическая модель процесса аккумуляции тепловой энергии в стационарном переключающемся регенеративном теплоутилизаторе // Фундаментальные исследования. - 2014. - № 11. - С. 759-764.

10. Шваб А.В., Марценко М.С. Исследование движения плотного слоя гранулированной среды и процесса смешения в сужающемся канале // Вестник Томского государственного университета. 2010 Математика и механика № 4(12). - С. 123-130.

11. Промышленная теплоэнергетика и теплотехника. Справочник / Под общ. ред. В.А. Григорьева, В.М. Зорина. - М.: Энергоатомиздат, 1991. - 588 с

12. Solodka A. V., Volgusheva N.V., Boshkova I. L., Titlov A. S., Rozhentsev A. V. Investigation of heat exchange in a blown dense layer of granular materials // EastEuropean Journal of Enterprise Technology: Energy-saving technologies and equipment. - 2017. -Vol 5, No. 8 (89).P. 58-64.

13. Василенко Ю. Н. Выбор теплообменника при интенсификации теплообмена путем увеличения площади поверхности теплопередачи между теплоносителями // Промышленная энергетика. - 2013. - №11. - с. 14-15.

14. Солодка А.В. Методики расчета контактных теплообменников с движущемся продуваемом плотном слое // Збірник наукових праць III Міжнародної науковотехнічної конференції «Холод в енергетиці і на транспорті: сучасні проблеми кондиціювання та рефрижерації, 24-25 вересня 2015. -Миколаїв, НУК ім. адмірала Макарова. - 2015 - С. 67-73.

\title{
Development of a heat exchanger with a fixed granulated filler for utilization of low potential heat
}

\author{
I. L. Boshkova, N. V. Volgusheva, A. V. Solodkava \\ Odessa National Academy of Food Technologies, 112 Kanatnaya St., Odessa, 65039, Ukraine
}

\begin{abstract}
Heat exchangers of regenerative type with a granulated filler intended for utilization of heat of exhaust gases are considered. It is noted that the use of flow disperse heat carriers allows to intensify the processes of heat exchange, which opens the prospect of using contact heat exchangers for utilization of low-potential off-gases heat. The technique of calculation thermal design of a heat exchanger with a fixed filler is presented. To determine the coefficient of intercomponent heat exchange, an empirical dependence was proposed in a dimensionless form, obtained as a result of processing experimental data on the study of heat exchange between the flow of gaseous heat transfer agent and a layer of solid particles. The results of calculating the heat exchanger according to the presented methodics are given. The values of the main geometric and physical characteristics are obtained: the volume of the heat exchanger, the height, the mass of the granular filler, and the duration of the heating period. Comparison with similar characteristics for a heat exchanger with a moving filler shows the advantage of the latter in thermal efficiency. However, when using a heat exchanger with a fixed packing, there is no need to organize a continuous movement of the layer of granular material, which greatly simplifies the operation and construction of the heat exchanger.
\end{abstract}

Keywords: Off-gases; Utilization; Heat exchanger; Granulated filler; Method of calculation; Efficiency. 


\section{References}

1.Prutskih D. A. 2009. Gidrodinamika i teploobmen v regeneratore s dispersnoy nasadkoy / Avtoreferat diss. na soiskanie uch. stepeni k. t. n. Spetsialnost: 05.14.04 Promyishlennaya teploenergetika. Voronezh, 22 p. (in Russian).

2. Medvedev, V. B. 2009. Modelirovanie i raschet teplovyih protsessov $\mathrm{v}$ regenerativnyih utilizatorah teplotyi $\mathrm{s}$ tsirkuliruyuschey granulirovannoy nasadkoy : avtoref. dis. ... k.t.n.: 05.17.08 / V.B. Medvedev; [Ivanovskiy gos. energeticheskiy univ-t], Ivanovo, 17 p. (in Russian).

3. Yulong D., Yurong H., Wei Ngoc Y. 2008. Hydrodynamics and heat transfer of gas-solid two-phase mixtures flowing through packed beds. Progress in Natural Science, vol. 18, 1185-1196.

DOI: https://doi.org/10.1016/j.pnsc.2008.03.023

4. Snider D. M., Dale M. S. 2007.Three fundamental granular flow experiments and CPFD predictions, Power Technology, Vol. 176, 36-46.

DOI: https://doi.org/10.1016/j.powtec.2007.01.032

5. Reva L.S. 1984. Metody gidrodinamicheskogo i teplovogo rascheta teploobmennikov s zernistoi nasadkoi: diss. ... kand. tehn. nauk. Volgograd. - 260 p. (in Russian) 6. Yu J., Zhang M., Fan W., Zhou Y., Zhao G. 2014. Study on performance of the ball packed-bed regenerator: experiments and simulation. Applied Thermal Engineering, Vol. 69, 113-122.

7. Nie X. D., Besant R. W., Evitts R. W. 2010. Heat transfer between gas-solid phases within packed particle beds. Particulate science and technology: an international journal, Vol. 29, iss. 2, 151-162.

DOI: https://doi.org/10.1080/02726351.2010.536302

8. Boshkova I.L., Solodka A.V. 2016. Issledovanie effektivnosti teploobmena v teploobmennikah-utilizatorah s granulirovannoy nasadkoy // Aspektyi regionalnogo razvitiya MaterIali mIzhnarodnoYi naukovoYi
konferentsIYi. Moldova, KishinIv: Institut energetiki AN Moldovy. P. 373-377. (in Russian).

9. Monarkin N.N., Naimov A.N., Sinitsyin A.A., Rogulina T.V. 2014. Matematicheskaya model protsessa akkumulyatsii teplovoy energii $\mathrm{v}$ statsionarnom pereklyuchayuschemsya regenerativnom teploutilizatore // Fundamentalnyie issledovaniya. No. 11. S. 759-764. (in Russian)

10. Shvab A.V., Martsenko M.S. 2010. Issledovanie dvizheniya plotnogo sloya granulirovannoy sredyi i protsessa smesheniya v suzhayuschemsya kanale. Vestnik tomskogo gosudarstvennogo universiteta. Matematika $i$ mehanika, No. 4(12). P. 123-130. (in Russian).

11. Promyishlennaya teploenergetika i teplotehnika. 1991. Spravochnik / Pod obsch. red. V.A. Grigoreva, V.M. Zorina. M.: Energoatomizdat, 588 p. (in Russian).

12. Solodka A. V., Volgusheva N.V., Boshkova I. L., Titlov A. S., Rozhentsev A. V. 2017. Investigation of heat exchange in a blown dense layer of granular materials. East-European Journal of Enterprise Technology: Energysaving technologies and equipment. Vol 5, No. 8 (89), 58-64. (in Russian).

13. Vasilenko Yu. N. 2013. Vyibor teploobmennika pri intensifikatsii teploobmena putem uvelicheniya ploschadi poverhnosti teploperedachi mezhdu teplonositelyami. Promyishlennaya energetika, No.11, 14-15. (in Russian).

14. Solodka A.V. 2015. Metodiki rascheta kontaktnyih teploobmennikov s dvizhuschemsya produvaemom plotnom sloe. Zbirnik naukovih prats III Mizhnarodnoyi naukovo-tehnIchnoyi konferentsiyi «Holod v energetitsi i na transporti: suchasni problemi konditsiyuvannya ta refrizheratsiyi, 24-25 veresnya 2015. Mikolayiv, NUK im. admirala Makarova. P. 67-73. (in Russian).

Received 22 December 2017 Approved 07 February 2018 Available in Internet 28 February 2018 